\title{
Preparation and Characterization of New Micro-Composites Derived from Polyamide and Silica Sol
}

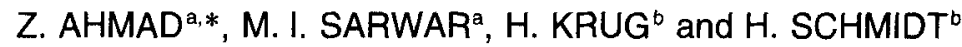 \\ aDepartment of Chemistry, Quaid-i-Azam University, islamabad 45320, \\ Pakistan; 'Dnstitut für Neue Materialien, Im Stadtwald, Gebäude 43, \\ Saarbrücken, D-66123, Germany
}

(Received 7 April 1997)

\begin{abstract}
New class of inorganic-organic hybrid micro-composites were prepared by the introduction of different proportions of colloidal silica particles into the polyamide matrix. Poly(phenyleneterephthalamide) was prepared by reacting a mixture of $\mathrm{m}$ - and $\mathrm{p}$ phenylenediamines with terephthaloyl chloride in dimethyl acetamide. Colloidal silica particles were obtained separately through sol-gel process by controlling the hydrolysis and condensation steps using tetraethoxysilane, ethanol, fuming $\mathrm{HCl}$ and water. Various proportions of the resulting sol were mixed with the polymer solution. $1 \%$ aminophenyltrimethoxysilane was added as a coupling agent in each case. Films were cast by evaporating the solvent and these films up to $5 \%$ wt. silica were yellow, tough and transparent, whereas the films with $7.5 \%$ wt. silica or more were off-white in color and opaque. Mechanical properties of these films were analyzed. The values of tensile strength, maximum strain at rupture, initial modulus and toughness were initially found to increase and then decrease with further addition of silica. The maximum tensile stress was observed with 5\% wt. silica (204 MPa) and tensile modulus was found in the range of 2.70 to $3.74 \mathrm{GPa}$ at $25^{\circ} \mathrm{C}$. Dynamic mechanical thermal analysis was carried out on the samples and the $\tan \delta$ data showed an increase in $\mathrm{Tg}$ with increase in silica contents. The storage modulus was found to be in the range of 9.55 to $10.25 \mathrm{GPa}$ at $100^{\circ} \mathrm{C}$.
\end{abstract}

Keywords: Hybrid composites; aramids; silica sol; tensile strength; DMTA

\section{INTRODUCTION}

Significant efforts have been made recently to utilize polymers and ceramics to produce novel inorganic-organic hybrid composites,

\footnotetext{
*Corresponding author, E. mail: zahmad@polychem.sdnpk.undp.org.
} 
frequently called 'ceramers'. Ceramics are useful due to their high thermal stabilities, strengths and high moduli, but are usually very brittle. Polymers, on the other hand, are much easier to process and are very tough but are thermally less stable. A suitable combination of inorganic-organic hybrid materials provide a way of exploiting the advantages of these rather disparate materials. There are many examples [1] of reinforcing fillers (inorganic oxides particles) with organic polymers in heterogeneous system. In these systems, the sizes of particles treated are of the order of micrometers. Mechanical mixing is used to disperse the particles thoroughly into organic material to provide a more homogeneous composites. The aromatic polyamides known as 'Aramids' have considerable advantages over the aliphatic polyamides, particularly useful as high-performance material because of their very high thermal stabilities and specific strengths, their high degree of stiffness and their low densities. For example, the fibers drawn from Nomex ${ }^{8}$ and Kevlar $^{\text {B }}$ have exceptional strength coupled with excellent high temperature properties; and because of their low densities, they are more than competitive with steel and glass fiber in many applications. Although the aramids have already excellent properties yet it is very useful to improve them further. This may perhaps be carried out better using metal alkoxides or sol [2]. The sol-gel technique, a chemically-based route $[3-14]$ to prepare ceramic materials is now being greatly used by ceramists. The microstructure of the porous metal oxide obtained using the sol-gel process is dependent on the kinetics of the hydrolysis and condensation reactions, which are largely controlled by the $\mathrm{pH}$ of the solution [15-17], the water to metal alkoxide ratio [18], the type of solvent and the nature of the alkoxy groups $[19,20]$. Present authors have used the sol-gel process for reinforcing the aramid matrix with inorganic ceramics such as silica [21-23], titania [24,25], zirconia [26] and alumina [27]. In-situ generated chemically bonded reinforcing phase to aramid through aminophenyltrimethoxysilane provided transparency as well as excellent improvement in the mechanical properties [28]. Starting from inorganic precursors, like alkoxides, soluble oxides or hydroxides, a growth process is initiated leading to colloids or aggregation. By control of this reaction, it is possible to stabilize intermediates in solution (sol). The colloidal particles thus produced can also be used in the organic matrices for reinforcement. 
In the transformation of metal alkoxides to oxides, Guglielmi and Carturan [29] have pointed out that hydrolysis is the most important factor for their success as precursors in the sol-gel process [29]. To improve processing we may complex alkoxides or even simple salts with organic ligands. Solubility can be increased and reactivity can be decreased. In order to obtain a clear sol from these inorganic containing metal alkoxides systems based on aluminium, titanium, and zirconium (all three of whcih show a relatively fast hydrolysis rate), chelating ligands such as glycols, organic acids, and $\beta$-dicarbonyl ligands have been utilized in conjunction with these systems [29-31]. Titania sol have been reported by LaCourse and Livage [32,33] through the complex formation of acetylacetonate or ethyl acetoacetate with titanium alkoxide. Suzuki and Onozato [34] have prepared an alumina sol from aluminium iso-propoxide. The alkoxide was hydrolyzed and resultant hydrate was peptized to a clear sol. From this sol and poly (vinyl alcohol) (PVA), composite material was prepared which were transparent in whole content of alumina. The composites containing PVA $40-50 \%$ were flexible. Wilkes and coworkers [35] have synthesized transparent flexible hybrid network "ceramer" materials by incorporating triethoxysilane capped polytetramethylene oxide with highly reactive titanium isopropoxide or zirconium n-propoxide without chelating agents. The titania and zirconia sols were prepared, by slowly adding water containing acidified $(\mathrm{HCl})$ alcohol solution to metal alkoxide systems to avoid precipitation. These procedures to prepare the metal alkoxide sols are similar to Kamiya's method [36]. Tetramethoxysilane have generally been employed in most cases as the inorganic component due to its relatively slow and controllable rate of reaction (hydrolysis/condensation).

In order to obtain hybrid materials, a suitable solvent having compatibility with the polymer and the sol is necessary. Poly (phenyleneterephthalamide), which is used to prepare $\operatorname{Kevlar}^{\Theta}$ fibers could have been used to prepare mechanically strong ceramers but the problem with this polymer is that it is not soluble in organic solvents. By introducing few meta linkages in such polymer chains, however, it is possible to keep the resulting copolymer in solution $[37,38]$. In the present study, the polymeric matrix was derived from this copolymer prepared by reacting a mixture of $\mathrm{m}$ - and $\mathrm{p}$ - phenylenediamines with terephthaloyl chloride in dimethyl acetamide. 
In order to provide reinforcement the sol of silica was used. It was prepared from tetraethoxysilane and ethanol by controlling the hydrolysis and condensation steps using fuming $\mathrm{HCl}$ and distilled water. Various proportions of this sol were mixed with polymer solution. $1 \%$ aminophenyl-trimethoxysilane (coupling agent) was added to the mixture to develop physical interactions between the polymer matrix and inorganic phase. Films were then cast from these materials and their mechanical properties, dynamic mechanical thermal analysis were studied.

\section{EXPERIMENTAL}

\subsection{Materials}

The monomers 1,4-phenylenediamine, 1,3-phenylenediamine, and terephthaloyl chloride (TPC), and the solvent dimethyl acetamide (DMAC) were all obtained from Fluka as AR-grade materials. Ethanol (absolute) and fuming $\mathrm{HCl}$ were obtained from Fluka, and tetraethoxysilane (TEOS), 99\% pure, and aminophenyltrimethoxysilane (APTMOS), 97\% pure were obtained from Gelest, Inc. All were used as received.

\subsection{Preparation of Aramid}

A mixture of 1,4-and 1,3-phenylenediamines, $5.446 \mathrm{~g}(0.050 \mathrm{~mol})$ in a mole ratio of 35:65 was placed into a $250 \mathrm{ml}$ conical flask under anhydrous conditions. DMAC $(146.0 \mathrm{ml})$ was added in the flask as a solvent. After complete mixing the amine solution was cooled to $0^{\circ} \mathrm{C}$ and $10.151 \mathrm{~g}(0.050 \mathrm{~mol})$ of TPC added under anhydrous conditions. After about $30 \mathrm{~min}$ of reaction time the temperature of the mixture was allowed to rise to room temperature. The reaction between diamines and diacid chloride is extremely fast and no change in viscosity is observed after $30 \mathrm{~min}$ of reaction at $25^{\circ} \mathrm{C}$. The reaction, therefore, was assumed to be complete [39] after $24 \mathrm{hrs}$. By keeping the weight ratio of the monomers to about $8-10 \%$ of the total reaction mixture it was possible to attain a high molecular weight aramid with good mechanical strength. Using dimethyl acetamide as solvent had an 
advantage as its solvating power increases due to the formation of a complex with $\mathrm{HCl}$ (produced during the reaction) and no precipitation occurs as the molecular weight builds up [40]. 1\% aminophenyltrimethoxysilane was added to the polymer solution to act as coupling agent between organic and inorganic phases. The polymer solution thus prepared served as a stock solution.

\subsection{Preparation of Silica Sol}

In complete dry conditions, $17.11 \mathrm{~g}(0.075 \mathrm{~mol})$ of TEOS and $114.00 \mathrm{~g}$ of ethanol were mixed thoroughly for $10 \mathrm{~min} .1 .48 \mathrm{~g}$ of fuming $\mathrm{HCl}$ was then added dropwise with continuous stirring for 20 minutes. It was followed by a dropwise addition of $1.77 \mathrm{~g}$ of distilled water. Stirring was continued for $3 \mathrm{hr}$. The resulting solution was a clear sol of silica.

\subsection{Preparation and Characterization of Hybrid Material}

Various proportions of the silica sol were added to the polyamide solution. Stirring of the reaction mixture continued for further $6 \mathrm{hrs}$ at $60^{\circ} \mathrm{C}$. Films with thickness varying from 0.012 to $0.015 \mathrm{~mm}$ were cast from the samples containing various amounts of silica by baking out the solvent in an oven at $75-80^{\circ} \mathrm{C}$. The films thus produced, were soaked in water to leach out any $\mathrm{HCl}$ produced during polymerization. These films were then dried at $80^{\circ} \mathrm{C}$ under vacuum for $72 \mathrm{hrs}$. Mechanical properties of these films were studied using a tensile testing instrument (Instron Universal Testing Instrument Model TM-SM 1102 $\mathrm{UK}$ ) at $25^{\circ} \mathrm{C}$ with a strain rate of $0.5 \mathrm{~cm} / \mathrm{min}$. Dynamic mechanical thermal analysis was carried out (Rheometric Scientific DMTA III) in the temperature range 100 to $500^{\circ} \mathrm{C}$ using a frequency of $10 \mathrm{MHz}$.

\section{RESULTS AND DISCUSSION}

The pure aramid film and aramid-silica hybrid films up to $5 \mathrm{wt} . \%$ silica were yellow, tough and transparent. The films with more than $5 \mathrm{wt} . \%$ silica were off-white in color and opaque. Increased amount of silica reduced the transparency of the films to opaqueness. In our previous work [28], where the inorganic network (silica) was produced 
in-situ in the polymer matrix and the aramid chains with carbonyl chloride end groups were chemically endlinked through aminophenyltrimethoxysilane with the inorganic network, the films obtained from these chemically bonded systems were yellow in color and transparent up to $25 \mathrm{wt}$. \% silica. These observations have clearly indicated that when physical interactions were developed between the sol and the matrix, the transparency as compared to the chemically bonded system was less. The sol particles tend to agglomerate [41] and possibly the distribution in the matrix become irregular as the percentage of silica is increased and this increases the magnitude of the scattering and the associated opaqueness.

The stress-strain curves of pure aramid and aramid-silica composites materials with $2.5-30$ wt. \% silica are shown in Figure 1 . It is clear from the Figure 1 that the tensile strength of the hybrid material increases initially with increase in silica contents and then decreases at higher amounts of silica. The value obtained for pure polymer was 172 $\mathrm{MPa}$ which increased to $204 \mathrm{MPa}$ for the composites containing $5 \%$

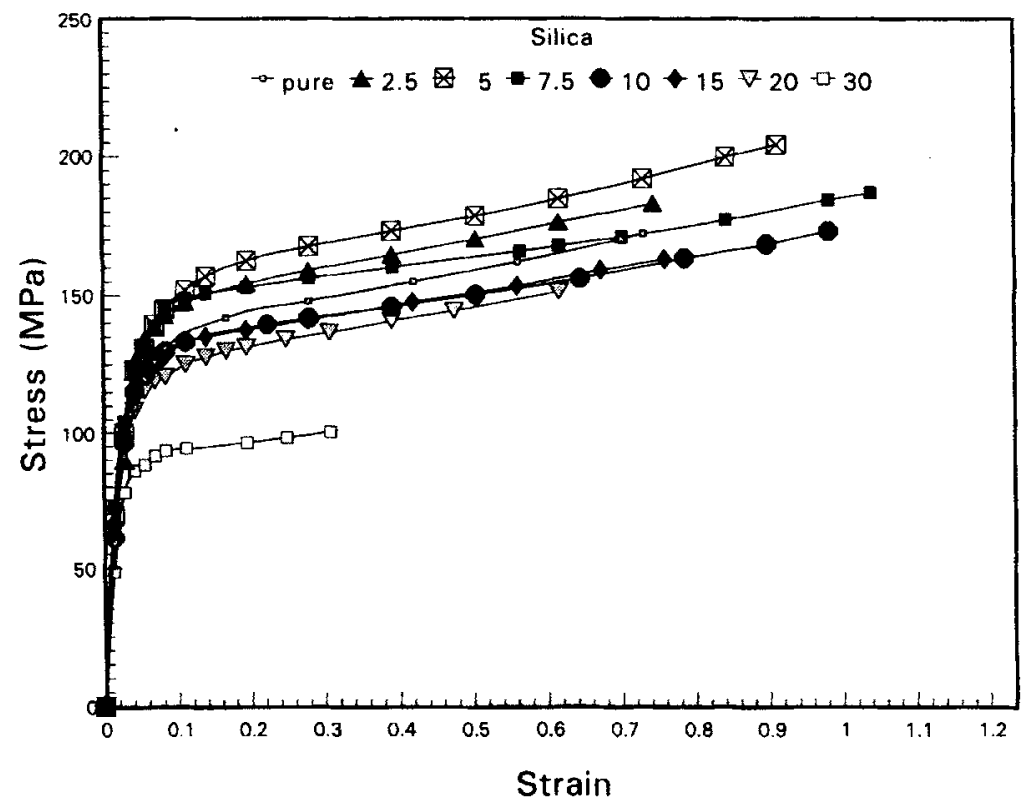

FIGURE 1 Tensile strength of aramid-silica composites containing different percentages of silica. 
wt. silica (Tab. I). The ultimate stress at rupture for these ceramers increases initially and then decreases with higher silica contents. It was maximum i.e., $204 \mathrm{MPa}$ with 5\% wt. silica (Tab. I and Fig. 2). The elongation at break point slightly increases at the beginning and then decreases with higher proportion of silica (Tab. I and Fig. 3). These results indicate an improvement in tensile strength of hybrid materials

TABLE I Max. stress and max. strain of aramid-silica composites containing different percentages of silica

\begin{tabular}{lccc}
\hline No. & $\begin{array}{c}\text { SiO }_{2} \text { contents }(\%) \\
\text { in aramid }\end{array}$ & $\begin{array}{c}\text { Max. stress } \\
(\text { MPa })\end{array}$ & Max. strain \\
\hline 1 & 0.0 & 172 & 0.720 \\
2 & 2.5 & 183 & 0.745 \\
3 & 5.0 & 204 & 0.913 \\
4 & 7.5 & 187 & 1.040 \\
5 & 10.0 & 173 & 0.983 \\
6 & 15.0 & 163 & 0.760 \\
7 & 20.0 & 151 & 0.618 \\
8 & 30.0 & 100 & 0.309 \\
\hline
\end{tabular}

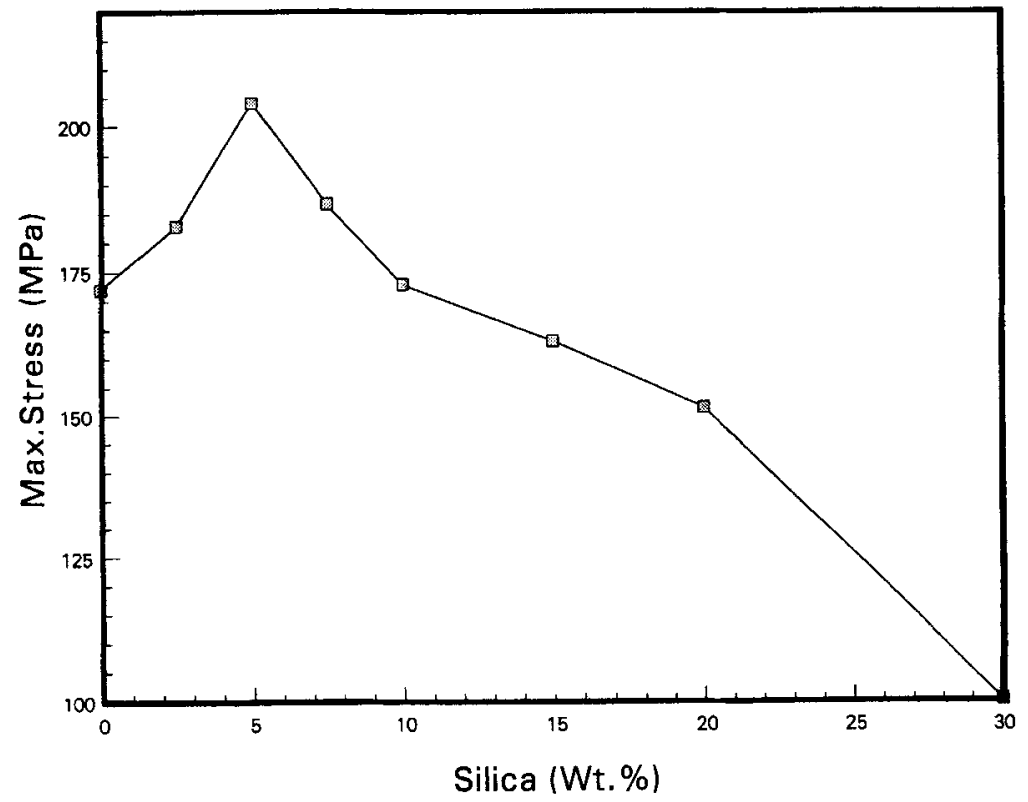

FIGURE 2 Max. Stress at break vs percent silica in aramid-silica composites. 


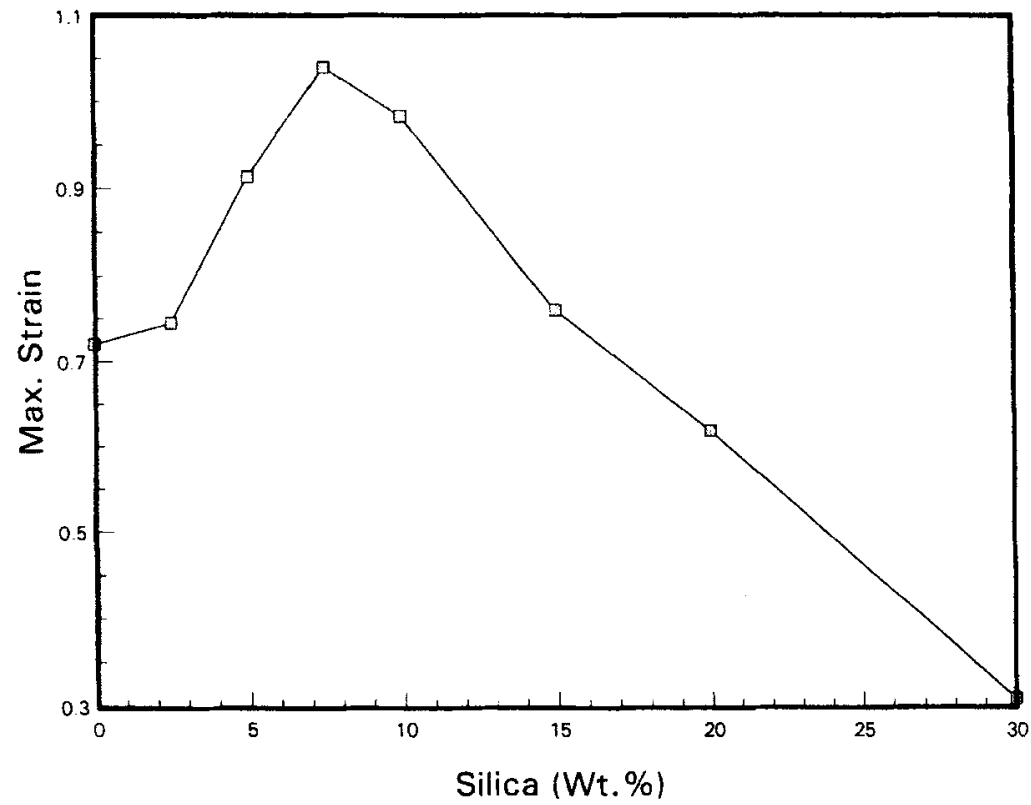

FIGURE 3 Maximum Strain at break vs percent silica in aramid-silica composites

relative to that the pure aramid. The introduction of inorganic material into the polymer matrix reinforces the polymer up to a certain limit and then further addition of this inorganic network decreases this property. The organic phase, which generally has a large free volume and low glass transition temperature, can not withstand high stresses. On the other hand, the inorganic phase, which generally associated with a small free volume and high glass transition temperature, has the capability of tolerating large stresses. The intimate blending of the two phases, results in a combination of some of the best properties of the two components. However, as the inorganic network become extensive particle size increases and the distribution become irregular. The inorganic large particles are of porous nature so the mechanical properties of the composites, deteriorates at higher silica contents.

The initial moduli calculated by measuring the initial slopes of the stress-strain data are shown in Figure 4 . The pure aramid had a value of tensile modulus $2.70 \mathrm{GPa}$ which increased to a maximum value 


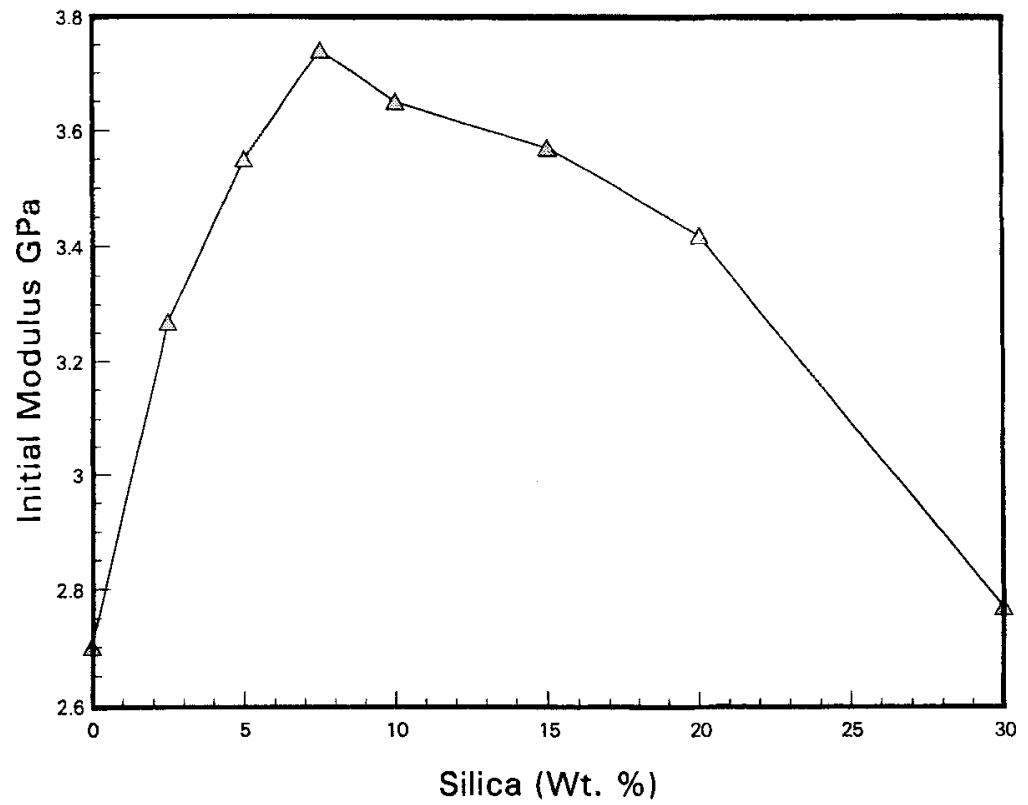

FIGURE 4 Initial Modulus vs percent silica in aramid-silica composites.

TABLE II Initial modulus and toughness of aramid-silica composites containing different percentages of silica

\begin{tabular}{lccc}
\hline No. & $\begin{array}{c}\mathrm{SiO}_{2} . \text { contents } \\
\text { in aramid }\end{array}$ & $\begin{array}{c}\text { Initial modulus } \\
(\mathrm{GPa})\end{array}$ & $\begin{array}{c}\text { Toughness } \\
(\mathrm{MPa})\end{array}$ \\
\hline 1 & 0.0 & 2.70 & 100.30 \\
2 & 2.5 & 3.27 & 114.82 \\
3 & 5.0 & 3.55 & 146.45 \\
4 & 7.5 & 3.74 & 162.61 \\
5 & 10.0 & 3.65 & 139.60 \\
6 & 15.0 & 3.57 & 106.60 \\
7 & 20.0 & 3.42 & 76.82 \\
8 & 30.0 & 2.77 & 23.40 \\
\hline
\end{tabular}

3.74 GPa with $7.5 \%$ wt. Silica, beyond this it decreased due to brittle nature of material (Tab. II). Toughness of these materials was measured by calculating the area under the stress-strain data, is described in Figure 5. These values are given in (Tab. II). These values which show an increase initially were also found to decrease with higher silica content. 


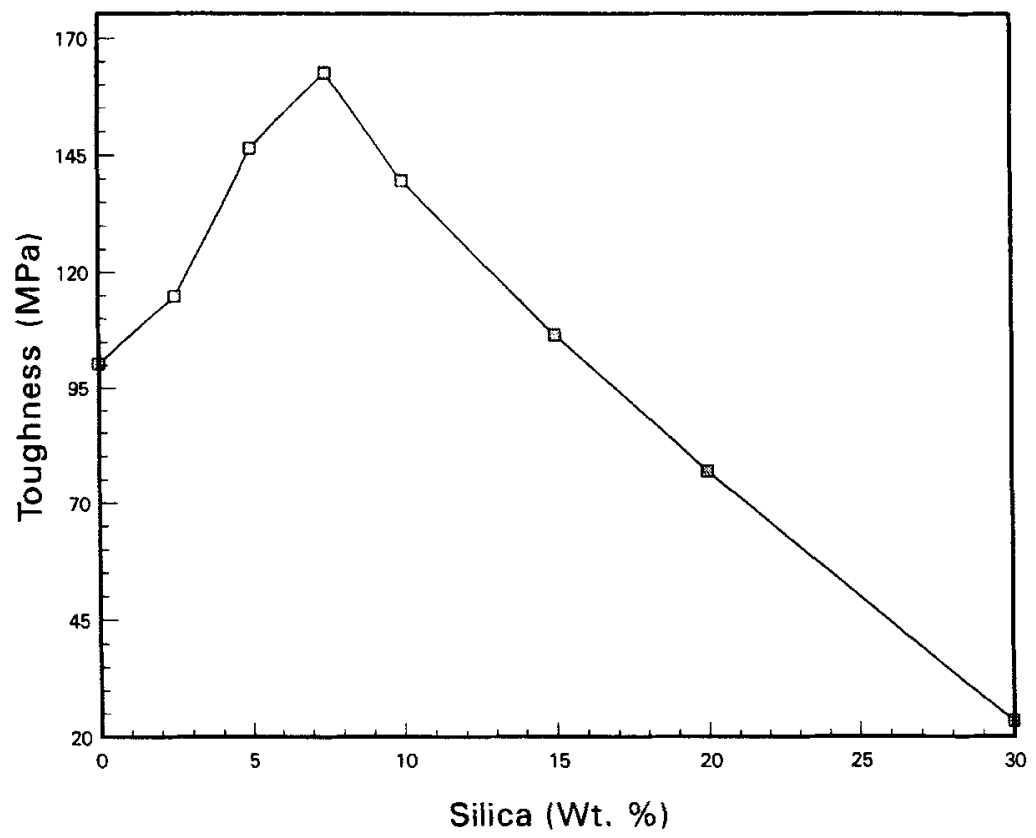

FIGURE 5 Toughness vs percent silica in aramid-silica composites.

Dynamic mechanical thermal analysis was used to determine the glass transition temperature $\left(T_{g}\right)$ and storage moduli $\mathrm{E}$ in the range of $100-500^{\circ} \mathrm{C}$ at a fixed frequency of $10 \mathrm{MHz}$. The temperature dependence storage modulus (bending) is given in Figure 6. The storage modulus initially increases with increase in silica contents due to the completion of inorganic network through condensation process at higher temperature and then slightly decreases on further increase in temperature due to the flexibility of the polymer matrix. The increased proportion of the silica increase the storage modulus up to a point beyond which, however, the inorganic phase increase the brittleness to the extent of lowering the modulus. Increase in the modulus beyond $400^{\circ} \mathrm{C}$ is due to crosslinking of the polymeric chains due to the production of free radicals produced at higher temperature.

The variation of the loss $\tan \delta$ with temperature for pure aramid, and for aramid-silica colloidal hybrid materials are given in Figure 7. The pure aramid shows a peak at $320^{\circ} \mathrm{C}$. In case of the hybrid materials with different percentages of inqrganic structures, however, this 


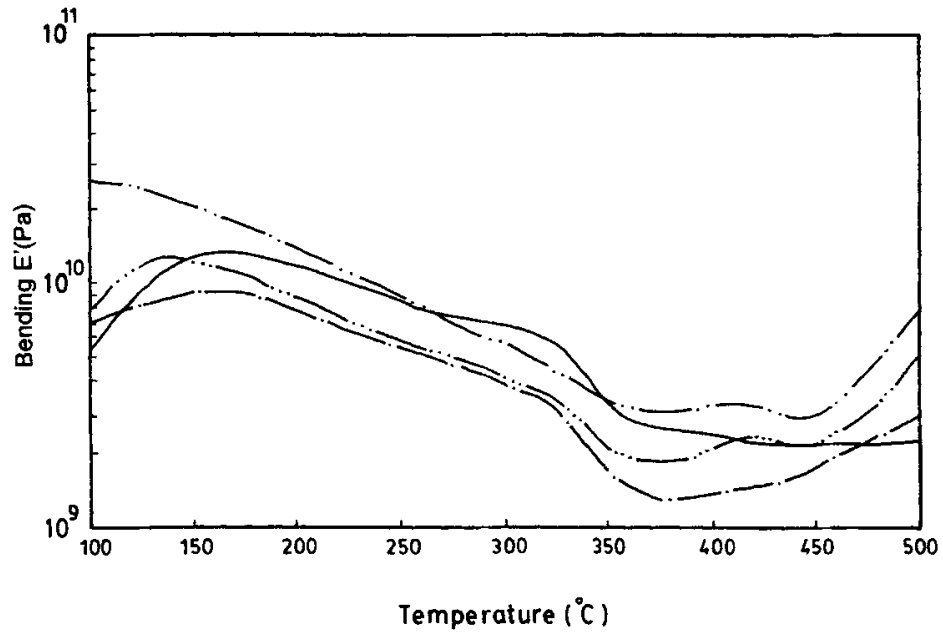

FIGURE 6 Temperature dependence of storage modulus for aramid-silica composites at $10 \mathrm{MHz}$, silica \% in aramid: $0(-), 7.5(-\cdots) 15(-\cdots),, 20(-\cdots-)$.

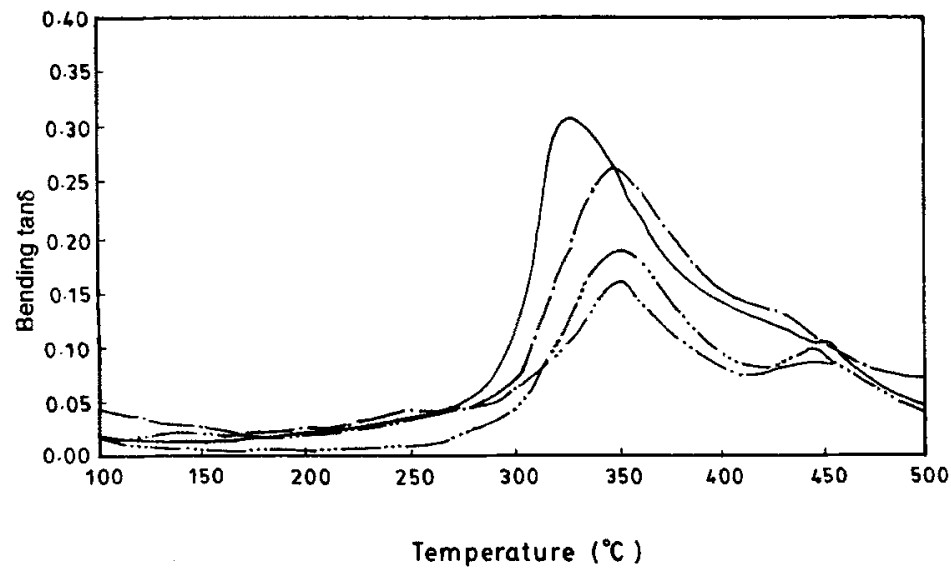

FIGURE 7 Variation of the loss tangent $(\tan \delta)$ with temperature for aramid-silica composites at $10 \mathrm{MHz}$., silica \% in aramid: $0(-), 7.5(-.-), 15(-\cdots-), 20(-\cdots-)$.

peak splits up into two portions, showing a maxima around $350^{\circ} \mathrm{C}$ and then a shoulder at higher temperature. These sharp peaks for the composite materials are observed at slightly higher temperatures than those for the pure aramid. The addition of silica shifts the peaks to 
some extent because the inorganic network hinders segmental motions of the polymer chains. The shift in the $T_{g}$ values is less pronounced because silica network has only physical bonding with aramid chains.

Figure 8 shows the variation of the loss $\tan \delta$ with temperature for pure aramid, and for the in-situ generated aramid hybrid materials chemically bonded with the silica network. With addition of silica, the single sharp peak of the aramid again splits into a peak and a broad shoulder, with the shoulder shifting to higher temperatures with increase in silica contents. A comparison among the Figures 7,8, clearly indicates that the shift of $\tan \delta$ to higher temperatures are significantly larger in the chemically-bonded systems $[28,42]$. The difference suggests increased adhesion between the polymer and the silica. The composites having $10 \%$ silica shows a smooth, broader curve with no shoulder at all. The improved bonding is obviously the reason for the higher values of the tensile strength for films having $7-10 \%$ silica, as compared to that of the pure aramid [28].

The present work shows that our previously in-situ generated aramid-silica composites were better than newly prepared composites in which already prepared silica sol was mixed in different proportions in the aramid matrix.

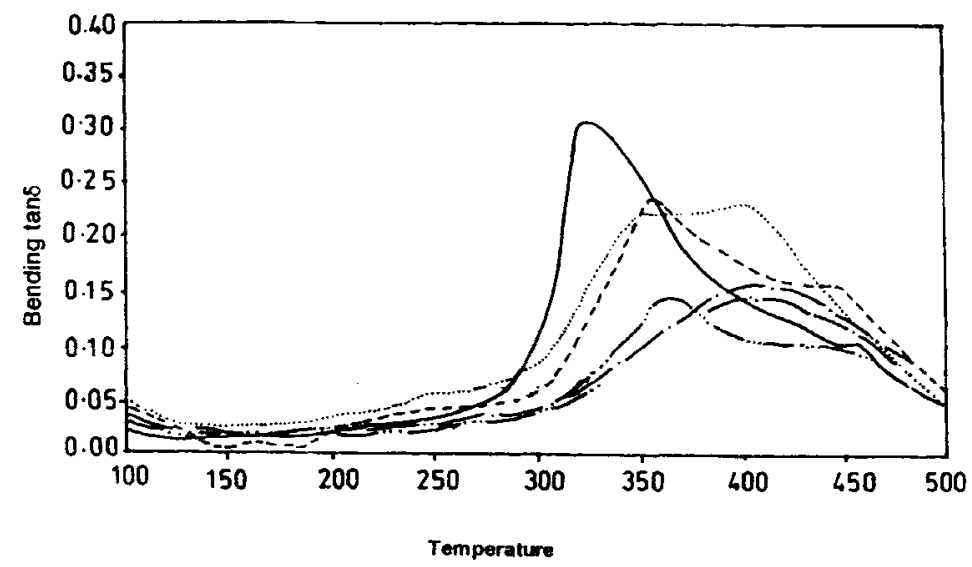

FIGURE 8 Variation of the loss tangent $(\tan \delta)$ with temperature for chemically bonded aramid-silica composites at $10 \mathrm{MHz}$., silica \% in aramid: $0(-), 5(\cdots \cdots \cdots), 7.5$ $(-\ldots), 10(-.-), 15(-\cdots-), 20(-\cdots-)$. 


\section{References}

[1] Van Olephen, H. (1977). AV Introduction to Clay Colloidal Chemistry, Wiley, New York, Greenberg, A. R. and Kamel, I. (1977). J. Polym. Sci. Polym. Chem. Eds., 15, 2137.

[2] Hino, T., Mochida, K. and Okamura, S. (1983). Kobunshi Ronbunsyu, 40, 2252.

[3] Uhlmann, D. R. and Ulrich, D. R. (1992). Eds., Ultrastructure Processing of Advanced Materials' Wiley, New York.

[4] Hench, L. L. and West, J. K. (1992). Eds. Chemical Processing of Advanced Materials' Wiley, New York.

[5] Schmidt, H. (1994). J. Sol-Gel Sci. and Tech., 1, 217.

[6] Betrabet, S. C. and Wilkes, G. L. (1994). J. Inorg. Organomet. Polym., 4, 343.

[7] Cheetham, A., Brinker, C. J., Mecartney, M. L. and Sanchez, C. (1994). Eds., Better Ceramic Through Chemistry VI, Material Research Society, Pittsburgh, 346.

[8] Klein, L. C. (1994). Ed., Sol-Gel Optics, Kluwer Academic Publishers, Boston.

[9] Schmidt, H., Kasemann, R., Burkhart, T., Wagner, G., Arpac, E. and Geiter, E. (1995). ACS Symp. Ser. on Hybrid Organic-Inorganic Composites, 585, 331.

[10] Mascia, L. (1995). Trends Polym. Sci., 3, 61.

[11] Gaw, K., Suzuki, H., Kakimoto, M., Imai, and Yoshio, (1995). J. Photopolym. Sci. Technol., 8, 307.

[12] Ahmad, Z., Sarwar, M. I. and Mark, J. E. (1997). J. Mater. Chem., 7(2), 259.

[13] Mark, J. E., Lee, C. Y.-C. and Bianconi, P. A. (1995). Eds., Hybrid Organic-Inorganic Composites, American Chemical Society, Washington, 585.

[14] Mark, J. E. (1996). Polym. Eng. Sci., 36, 000

[15] Yamame, M., Inoue, S. and Yasumoori, A. (1984). J. Non-Cryst. Solids., 63, 13.

[16] Brinker, J. C., Keefer, D. K., Schaefer, W. D., Assink, A. T., Kay, D. B. and Ashley, S. C. (1984). J. Non-Cryst. Solids, 63, 45.

[17] Pope, A. J. E. and Mackenzine, D. J. (1986). J. Non-Cryst. Solids, 87, 185.

[18] Sakka, S. and Kamiya, K. (1989). in "Emergent Process Methods for High Technology Ceramics' (Eds., P. F. Davis, H. Palmour and R. L. Porter), Plenum Press, New York

[19] Mackenzie, D. L. (1986). in 'Scinence of Ceramic Chemical Processing' (Eds., L. L. Hench and D. R. Ulrich), Wiley, New York, p 113.

[20] Aelion, R., Loebel, A. and Eirich, F. (1950). J. Am. Chem. Soc., 72, 5705.

[21] Mascia, L. and Kioul, A. (1994). J. Mater. Sci. Lett., 13, 641.

[22] Ahmad, Z., Wang, S. and Mark, I. E. (1994). Chem. Mater., 6, 943

[23] Ahmad, Z., Wang, S. and Mark, J. E. (1994). J. Macromol. Sci., 31, 411.

[24] Wang, B. and Wilkes, G. L. (1994). J. Macromol. Sci., Pure Appl. Chem., 31, 249.

[25] Ahmad, Z., Sarwar, M. I., Wang, S. and Mark, J. E. Polymer, (in press).

[26] Rehman, H. U., Sarwar, M. I., Ahmad, Z., Krug, H. and Schmidt, H. (1997) J. Non-Cryst. Solids., 211, 105.

[27] Ahmad, Z., Sarwar, M. I., Krug, H. and Schmidt, H. Angew. Makromol Chemie, (in press).

[28] Ahmad, Z., Wang, S. and Mark, J. E. (1994). In 'Better Ceramic Through Chemistry VI' (Eds., Sanchez, C., Brinker, C. J., Mecartney, M. L. and Cheetham, A.) Materials Research Society, Pittsburgh, 346, p. 127.

[29] Guglielmi, M. and Cartouran, G. (1988). J. Non-Cryst. Solids., 100, 16.

[30] Bradley, D. C. (1967). Coord. Chem. Rev., 2.

[31] Schmidt, H. (1988). J. Non-Cryst. Solids., 100, 51.

[32] Doeuff, S. Henry, M., Sanchez, C. and Livage, J. (1987). J. Non-Cryst. Solids., 89, 206.

[33] LaCourse, W. C. and Kim, S. (1986). 'Science of Ceramic Chemical Processing' (Eds., Hench, H. L. and Ulrich, D. R.), Wiley, New York, p. 304

[34] Suzuki, F. and Onozato, K. (1990). J. Appl. Polym. Sci., 39, 371. 
[35] Wang, B. and Wilkes, G. L. (1991) J. Polym. Sci., 29, 905.

[36] Kamiya, K., Tanimoto, K. and Yoko, T. (1986). J. Mater. Sci. Lett., 402.

[37] Ahmad, Z., Wang, S. and Mark, J. E. (1993). Polym. Bull., 31, 323.

[38] Mark, J. E., Wang, S. and Ahmad, Z. (1995). Macromol. Symp., 98, 73.

[39] Preston, J. and Dobinson, F. (1964). Polym. Letters., 2, 1175.

[40] Morgan, P. W. (1963). J. Polym. Sci., Pant C, 4, 1075.

[41] Brennan, A. B. and Wilkes, G. L. (1991). Polymer, 32, 733.

[42] Ahmad, Z., Sarwar, M. I. and Mark, J. E. (1997). J. Appl. Polym. Sci., 63, 1345. 